\title{
A single amino acid residue substitution in BraA04g017190.3C, a histone methyltransferase, results in premature bolting in Chinese cabbage (Brassica rapa L. ssp. Pekinensis)
}

Chong $\operatorname{Tan}^{\dagger}$, Jie Ren ${ }^{\dagger}$, Lin Wang, Xueling Ye, Wei Fu, Jiamei Zhang, Meng Qi, Hui Feng and Zhiyong Liu* (D)

\begin{abstract}
Background: Flowering is an important inflection point in the transformation from vegetative to reproductive growth, and premature bolting severely decreases crop yield and quality.

Results: In this study, a stable early-bolting mutant, ebm3, was identified in an ethyl methanesulfonate (EMS)mutagenized population of a Chinese cabbage doubled haploid (DH) line ' $F T^{\prime}$. Compared with ' $F T^{\prime}$, ebm3 showed early bolting under natural cultivation in autumn, and curled leaves. Genetic analysis showed that the early-bolting phenotype was controlled by a single recessive nuclear gene. Modified MutMap sequencing, genotyping analyses and allelism test provide strong evidence that BrEBM3 (BraA04g017190.3 C), encoding the histone methyltransferase CURLY LEAF (CLF), was the strongly candidate gene of the emb3. A C to T base substitution in the 14th exon of BrEBM3 resulted in an amino acid change ( $\mathrm{S}$ to $\mathrm{F}$ ) and the early-bolting phenotype of emb3. The mutation occurred in the SET domain (Suppressor of protein-effect variegation 3-9, Enhancer-of-zeste, Trithorax), which catalyzes siteand state-specific lysine methylation in histones. Tissue-specific expression analysis showed that BrEBM3 was highly expressed in the flower and bud. Promoter activity assay confirmed that BrEBM3 promoter was active in inflorescences. Subcellular localization analysis revealed that BrEBM3 localized in the nucleus. Transcriptomic studies supported that BrEBM3 mutation might repress H3K27me3 deposition and activate expression of the AGAMOUS (AG) and AGAMOUS-like (AGL) loci, resulting in early flowering.
\end{abstract}

Conclusions: Our study revealed that an EMS-induced early-bolting mutant ebm3 in Chinese cabbage was caused by a nonsynonymous mutation in BraA04g017190.3 C, encoding the histone methyltransferase CLF. These results improve our knowledge of the genetic and genomic resources of bolting and flowering, and may be beneficial to the genetic improvement of Chinese cabbage.

Keywords: Brassica rapa, Flowering, MutMap, CURLY LEAF, EMS mutagenesis

\footnotetext{
* Correspondence: 2010500026@syau.edu.cn

${ }^{\dagger}$ Chong Tan and Jie Ren contributed equally to this work.

Liaoning Key Laboratory of Genetics and Breeding for Cruciferous Vegetable Crops, Department of Horticulture, Shenyang Agricultural University, 110866

Shenyang, People's Republic of China
}

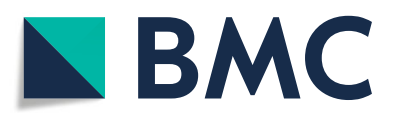

(c) The Author(s). 2021 Open Access This article is licensed under a Creative Commons Attribution 4.0 International License, which permits use, sharing, adaptation, distribution and reproduction in any medium or format, as long as you give appropriate credit to the original author(s) and the source, provide a link to the Creative Commons licence, and indicate if changes were made. The images or other third party material in this article are included in the article's Creative Commons licence, unless indicated otherwise in a credit line to the material. If material is not included in the article's Creative Commons licence and your intended use is not permitted by statutory regulation or exceeds the permitted use, you will need to obtain permission directly from the copyright holder. To view a copy of this licence, visit http://creativecommons.org/licenses/by/4.0/. The Creative Commons Public Domain Dedication waiver (http://creativecommons.org/publicdomain/zero/1.0/) applies to the data made available in this article, unless otherwise stated in a credit line to the data. 


\section{Background}

Flowering is a crucial developmental process that marks the transition from vegetative to reproductive growth, and is essential for propagation. The timing of floral induction is determined by the interaction of environmental and endogenous cues, ensuring that flowering occurs under the conditions the most likely to maximize offspring quantity and quality $[1,2]$. One goal of plant breeding is to improve plant adaptability to climate changes and new environment by controlling flowering time, to ultimately increase crop yield and quality. An enhanced understanding of the flowering regulatory network is of great value for crop genetic selection and improvement.

The genetic control of flowering time, including its interwoven network, has been extensively studied in the long-day (LD) model Arabidopsis thaliana and shortday (SD) model plant rice (Oryza sativa) [3]. In A.thaliana, six major genetic pathways controlling flowering time, i.e., photperiod, vernalization, autonomous, gibberellin, ambient temperature, and age, have been described [4]. Flowering is one of the most complex regulated pathways, the signaling cross-talk between the pathways induced flowering is ubiquitous. More specifically, such as cross-talk between vernalization and photperiod pathways ensures that plants adapt more effectively during unpredictable environmental condidtions [5]. In the floral induction phase, these pathways converge on floral integrator genes to control flowering time, thereby activating the downstream meristem identity genes. FLOWERING $T(F T)$ and SUPPRESSOR OF OVEREXPRESSION OF CONSTANS 1/ AGAMOUSLIKE 20 (SOC1/AGL20) are the two key floral integrator genes [6]. FT, which belongs to the phosphatidylethanolamine-binding protein (PEBP) family, has two homologs, namely TWIN SISTER OF FT (TSF) and TERMINAL FLOWER 1 (TFL1). And TSF and TFL1 act redundantly and antagonistically to FT, respectively. FT is produced in the leaves and is transported via the phloem to the shoot apical meristem (SAM), where it interacts with FLOWERING LOCUS D (FD) to induce SOC1 and the floral meristem identify genes APETALA 1 (AP1) and CAULIFLOWER (CAL) [7].

The photoperiod and vernalization pathways control flowering in response to seasonal changes in day length and temperature [8]. In the photoperiod pathway, $\mathrm{CON}$ STANS (CO) is the main positive regulator of FT/TSF. TEMPRANILLO (TEM) genes are reported to have a pivotal role in the direct repression of $F T$ and counteract the activator CO [9]. CYCLING DOF FACTORs (CDFs) are transcriptional repressors of CO. FLAVIN-BINDING KELCH REPEAT F-BOX 1 (FKF1) and GIGANTEA (GI) form a stable complex that releases repression of $C O$ by inducing degradation of $C D F 1$ [10]. At the posttranscriptional level, CONSTITUTIVE PHOTOMORPHOGENIC 1 (COP1) and SUPPRESSOR OF PHYTOCHROME A (SPA1) form a ubiquitin ligase complex that facilitates $\mathrm{CO}$ degradation in the dark [8]. LATE ELONGATED HYPOCOTYL (LHY) and CIRCADIAN CLOCK-ASSOCIATED1 (CCA1), are two MYB protein that play important roles in photoperiod pathway by controlling the rhythmic expression of floweringtime genes [11]. In the vernalization pathway, FLOWERING LOCUS C (FLC), which encodes a MADS-box transcription factor, acts as a central floral repressor by directly repressing the transcription of the floral promoting genes FT, SOC1/AGL20, and SQUAMOSA PROMOTER BINDING PROTEIN-LIKE 15 (SPL15) [12]. FRIGIDA (FRI), which encodes a coiled-coil protein, positively regulates $F L C$ by affecting its chromatin structure [13]. VERNALIZATION INSENSITIVE 3 (VIN3), which encodes a PHD-finger protein, is necessary for epigenetic silencing of FLC [14]. Two long noncoding RNAs (lncRNAs), cold-induced long antisense RNA (COOLAIR) and cold-assisted intronic noncoding RNA (COLDAIR), are responsible for transcriptional shutdown of FLC $[15,16]$. MADS AFFECTING FLOWERING (MAF), a member of FLC-like protein, can form protein complexs with FLC [17]. In addition, AGL19 has been found to promote flowering with interacting with FLC in vernalization pathway[18].

The effects of the autonomous, age, and gibberellin pathways are more independent of environmental stimuli. In the autonomous pathway, FCA, FY, FPA, FVE, FLOWERING LOCUS D (FLD), FLOWERING LOCUS KH DOMAIN (FLK), and LUMINIDEPENDENS (LD) participate in repressing $F L C$ to accelerate flowering [8]. In the age pathway, miR156-targeted SPL transcription factors and miR172-targeted APETALA 2 (AP2) and AP2-like genes are the two main modules [19]. AP2 and AP2-like genes inhibit the onset of flowering by repressing expression of (FRUITFULL) FUL/AGL8, SCO1/AGL20, and AG [20]. In $A$. thaliana, DELLAs are master negative regulators of gibberellin (GA) signal transduction. Upon binding to GA, GIBBERELLIN INSENSITIVE DWARF1 (GID1) undergoes a conformational change, which creates a surface for the binding of DELLAs to form a GA-GID1-DELLA complex. DELLAs are then recruited to E3 ubiquitin ligase $\mathrm{SCF}^{\mathrm{SLY1/GID2}}$ for polyubiquitination, leading to the degradation of DELLAs by the $26 \mathrm{~S}$ proteasome [21]. Furthermore, GA 20-oxidases (GA20ox1-5), GA 3-oxidases (GA3ox1-3), and GA 2-oxidases (GA2ox1-5) are involved in the GA pathway [8].

The ambient temperature pathway controls flowering in response to the daily growth temperature. SHORT VEGETATIVE PHASE (SVP) plays a key role in responding to changes in ambient temperature [22]. 
Brassica rapa closely related to $A$. thaliana, both belong to Brassicaceae family [8]. B. rapa shares $A$. thaliana's three paleo-polyploidy events $(\gamma, \beta$, and $\alpha)$, and experiences an additional whole genome triplication (WGT) event since the divergence from the last common ancestor with $A$. thaliana [23]. Thus, the genetic pathways controlling flowering time in B. rapa are more complex than those in $A$. thaliana because there are multiple copies of paralogs. Two paralogs of FT (BrFT1 and BrFT2) are found in B. rapa, and a transposon insertion in BrFT2 induces late flowering [24]. Three paralogs of SOC1 (Br004928, Br000393, and Br009324) are expressed, and at least two of them have been predicted to play a role in flowering in a natural population [25]. Overexpression of $\mathrm{BrSOC1/BrAGL20}$ in B. napus results in early flowering [26]. B. rapa comprises four $F L C$ genes, namely, $B r F L C 1, B r F L C 2$, $B r F L C 3$, and BrFLC5 [27]. BrFLC1, BrFLC2, and BrFLC3, syntenic orthologs of $A t F L C$, have been found to negatively regulate flowering [28-33]. A recent study has shown that BrFLC5 is a weak regulator of flowering time [34]. Two FRI paralogs in B. rapa, BrFRIa and BrFRIb, are activators of BrFLC [29]. In vernalized $B$. rapa, DNA demethylation of two subunits of casein kinase II (CK2), BrCKA2 and BrCKB4, shortens the period of $B r C C A 1$ [35]. In $B$. rapa, a pakchoi $M A F$ gene, $B c M A F 1$, delays flowering by directly activating $B c M A F 2$ and repressing $B c A P 3$ [36]. BCMAF2 can directly activate BCTEM1 and repress flowering [37]. Two B. rapa GI alleles are responsible for rescuing the late-flowering phenotype of an Arabidopsis gi-201 mutant [38].

Chinese cabbage is the most leafy B. rapa crop in East-Asian countries, composed of a large number of tightly wrapped heading leaves [39]. Flowering time is an important agronomic trait for Chinese cabbage, and premature bolting can severely reduce crop yield and quality. In the present study, we characterized an early-bolting Chinese cabbage mutant identified from an EMS-mutagenized population. By performing MutMap sequence, kompetitive allele-specific polymerase chain reaction (KASP) analyses, and allelism test, a nonsynonymous base substitution in $B r E B M 3$ was identified to cause the mutant phenotype. The expression pattern of the candidate gene BrEBM3 was comprehensively analyzed by evaluating spatiotemporal expression, promoter activity, and subcellular localization. Transcriptome profiling was conducted to identify potential BrEBM3-regulated genes responsible for flowering time in Chinese cabbage. We expected our findings to be of great significance for further study of the molecular mechanism of bolting and flowering in Chinese cabbage.

\section{Results}

\section{Morphological characteristics and genetic analysis of the mutant ebm3}

Following EMS treatment, $528 \mathrm{M}_{0}$ lines were obtained. By continuous identification and further screening for generations, the mutant ebm3 exhibiting obvious earlybolting characteristics in spring and autumn cultivation was selected as the study material. Except for curled leaves, the mutant emb3 showed no other pleiotropic effects when compared with the wild-type line 'FT' (Fig. 1a).

Under normal cultivation conditions in autumn, the wild-type line 'FT' will not prematurely bolt without exposure to a prolonged cold period (vernalization); however, but the mutant emb3 exhibited obvious bolting under these conditions (Fig. 1a). To more intuitively assess the characteristics of the mutant, three indices, squaring period (SP), flowering time (FT), and days to reaching a $10 \mathrm{~cm}$-high elongated floral stalk (DE), were measured in 30 individuals and the average values are presented. SP, FD, and DE of the mutant ebm3 were 40, 43 , and 46 days, respectively (Fig. 1b).

The reciprocal cross $F_{1}$ generation had the same phenotype as the wild-type line 'FT', indicating that the early-bolting phenotype of the mutant ebm3 was recessive and controlled by nuclear gene. In the $F_{2}$ generation, 1,225 and 401 individuals exhibited the wild-type line 'FT' and mutant ebm3 phenotype, respectively. This segregation ratio was consistent with the Mendelian ratio of $3: 1$ segregation $\left(\chi^{2}=0.08<\chi_{0.05}^{2}=3.84\right)$. In addition, all $518 \mathrm{BC}_{1}\left(\mathrm{~F}_{1} \times\right.$ 'FT') generation individuals exhibited the phenotype of the wild-type line 'FT'. For the $\mathrm{BC}_{1}\left(\mathrm{~F}_{1} \times\right.$ ebm3) generation, 264 and 272 individuals exhibited the wild-type line 'FT' and mutant ebm3 phenotype, respectively. This 1:1 segregation ratio was consistent with the expectations $\left(\chi^{2}=0.09<\chi_{0.05}^{2}=\right.$ 3.84). These data indicated that the phenotype of the mutant ebm3 was controlled by a single, recessive nuclear gene, named $B r E B M 3$, and its independent allele is Brebm3 (Table 1).

\section{Identification of the candidate gene of the mutant ebm3} We established three bulks to identify the bolting gene by a modified MutMap method [40]. The offspring pool comprised 15 plants exhibiting the mutant phenotype in the $\mathrm{F}_{2}$ population. The DNA of the offspring pool, wildtype 'FT' and mutant ebm3 was used to construct three libraries, designed as $\mathrm{F}_{2 \_} \mathrm{ebm} 3$, 'FT' and ebm3. The three libraries were resequenced. Sequencing produced 48.75 $\mathrm{Gb}$ of raw data. After filtering, $18.98 \mathrm{~Gb}, 9.19 \mathrm{~Gb}$, and $20.55 \mathrm{~Gb}$ clean data were obtained for the 'FT', ebm3, and $F_{2}$ ebm 3 library, respectively. Sufficient data were produced for each library, the sequencing data were of sufficient quality (Q20 $\geq 93.69 \%$, Q30 $\geq 88.04 \%$ ), and the GC distribution (37.55-42.77\%) was normal (Additional file 2: Table S1). The clean reads were aligned to the $B$. rapa reference genome (v3.0). The mapping rate was $97.95 \%, 97.37 \%$, and $97.31 \%$ for the 'FT', ebm3, and $F_{2}$ ebm3 library, respectively, corresponding to an average 
A

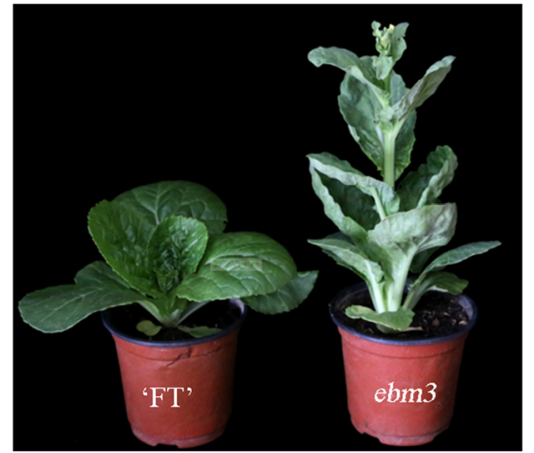

$\mathrm{C}$

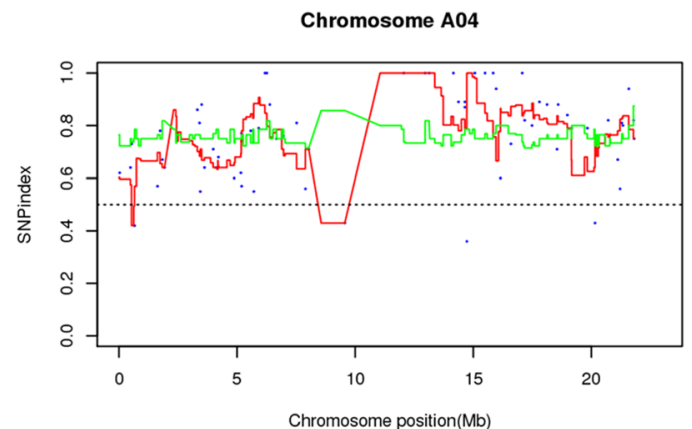

B

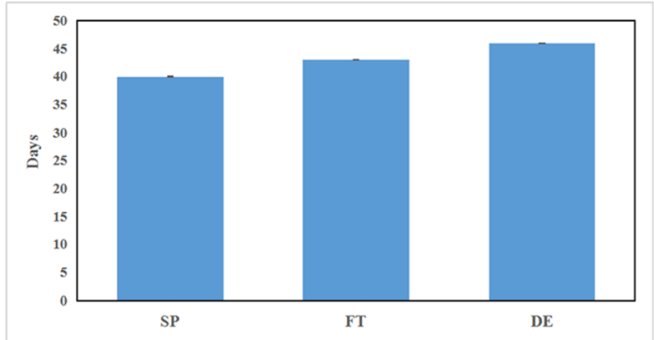

$\mathrm{D}$

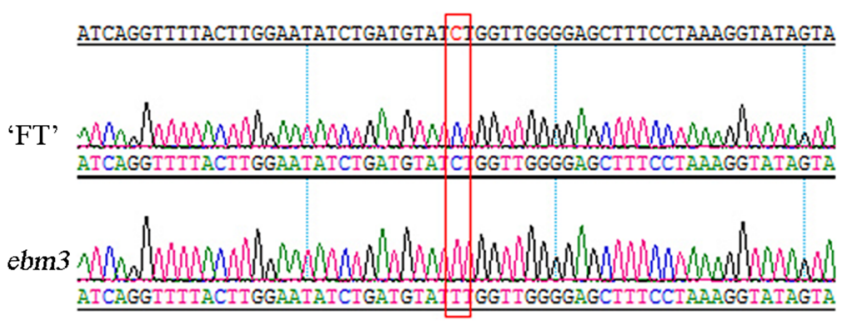

Fig. 1 Identification of the mutant ebm3 and candidate SNPs. a Phenotypic characterization of the wild-type line 'FT' (left) and the mutant ebm3 (right). The plants were photographed under DS-Fi3 microscope camera (Nikon Corporation, Japan). b Phenotypic values for mutant ebm3 under normal cultivation condition in autumn. SP represents squaring period. FT represents flowering time. DE represents $10 \mathrm{~cm}$-high elongated floral stalk. Sigmaplot software (Systat software, CA, USA) was used for statistical analysis. c The distribution of SNP index in offspring pool on chromosome A04 generated by MutMap analysis. Sliding window was performed with a simple perl script using a window size of $1 \mathrm{Mb}$ and a step size of $10 \mathrm{~Kb}$ as the default settings. $\mathbf{d}$ Sequencing peak of the C/T allele of SNP 13,129,878 generated by Sanger sequencing. The raw chromatogram data were analyzed using Chromas software

read coverage of 48.00, 22.46, and $21.17 \mathrm{X}$ (Additional file 2: Table S2). The mapped reads were normal and could be used for subsequent SNP detection. In total, 414,354 SNPs were detected in the 'FT' and ebm3 library, of which 457 homozygous nonsynonymous loci were gained to calculate SNP index in $\mathrm{F}_{2 \_}$ebm3 library. And then these loci that the SNP index $<0.3$ were filtered out. To evaluate the distribution of the SNP index physically mapped across the $B$. rapa chromosomes, we used an sliding window method with a $1 \mathrm{Mb}$ window size and $10 \mathrm{~Kb}$ step size in $\mathrm{F}_{2 \_}$ebm3 library. Here, we only showed the distribution of the SNP index in offspring pool on Chromosome A04, because it was the chromosome where the candidate loci were located (Fig. 1c). To further confirm the candidate loci, these above SNPs were screened as follows: retain loci with

Table 1 Genetic analysis of the early-bolting mutant ebm3 of Chinese cabbage

\begin{tabular}{|c|c|c|c|c|c|c|}
\hline Generation & ‘FT' & $e b m 3$ & Total & Segregation Ratio & Expected Ratio & $x^{2}$ \\
\hline$P_{1}\left({ }^{\prime} F T^{\prime}\right)$ & 92 & 0 & 92 & & & \\
\hline$P_{2}(e b m 3)$ & 0 & 81 & 81 & & & \\
\hline$F_{1}\left(P_{1} \times P_{2}\right)$ & 192 & 0 & 192 & & & \\
\hline$F_{1}\left(P_{2} \times P_{1}\right)$ & 184 & 0 & 184 & & & \\
\hline $\mathrm{BC}_{1}\left(\mathrm{~F}_{1} \times^{\prime} \mathrm{FT}^{\prime}\right)$ & 518 & 0 & 518 & & & \\
\hline $\mathrm{BC}_{1}\left(\mathrm{~F}_{1} \times e b m 3\right)$ & 264 & 272 & 536 & $0.97: 1$ & $1: 1$ & 0.08 \\
\hline $\mathrm{F}_{2}$ & 1225 & 401 & 1626 & 3.05: 1 & $3: 1$ & 0.09 \\
\hline
\end{tabular}


SNP index =1; filter out not-typical EMS mutant loci; retain loci large-effect. Finally, six SNPs $(3,407,432$, $6,258,734, \quad 13,129,878, \quad 18,591,168, \quad 21,580,928$ and $20,708,402$ ) were identified on chromosome A04, including five nonsynonymous sites in exons and one alternative splice site in an intron (Table 2).

To verify the reliability of these six mutated SNPs, the sequences surrounding them were amplified from DNA from the mutant ebm3 and wild-type line 'FT'. Sequence alignment results showed that all SNPs were real and the sequencing peak of the C/T allele of SNP 13,129,878 was displayed in Fig. 1d.

We conducted genotyping analysis of $200 \mathrm{~F}_{2}$ individuals to confirm the candidate SNP for the early-bolting mutant phenotype. A KASP assay showed that SNP 13,129,878 of BraA04g017190.3 C co-segregated with the mutant phenotype in the $\mathrm{F}_{2}$ individuals. All $\mathrm{F}_{2}$ individuals exhibited a $\mathrm{T}: \mathrm{T}$ genotype, whereas the wild-type line 'FT' was C:C genotype. For the other five SNPs, recombinants were detected in the $\mathrm{F}_{2}$ individuals, indicating these SNPs did not co-segregate with the mutant phenotype (Additional file 2: Table S3). These results confirmed that BraA04g017190.3 C, harboring SNP $13,129,878$, was the candidate gene of the mutant ebm3. Gene annotation confirmed that BraA04g017190.3 C encoded an important histone methyltransferase, homologous to CLF. Loss-of-function of A. thaliana CLF (At2g23380) causes an early flowering phenotype and upwardly curled leaves [41]. In this study, the candidate gene of the mutant ebm3 is referred to as $B r E B M 3$.

The full-length gene sequence of $B r E B M 3$ was found to be 4,406 bp, and BrEBM3 consists of 17 exons and 16 introns (Fig. 2a). Sequence alignment showed that besides SNP 13,129,878 in the 14th exon, there was no variation in the gene sequence and promoter sequence $(2,000 \mathrm{bp}$ upstream of the initiation codon) between the mutant ebm3 and wild-type line 'FT'. The coding sequence of BrEBM3, 2,715 bp in length, encodes a protein of 904 amino acids with a molecular weight of $1000 \mathrm{kDa}$ and a theoretical pI of 90.5. The SNP 13,129,878 $(\mathrm{C} \rightarrow \mathrm{T})$ of BrEBM3 causes an amino acid substitution from serine (S) to phenylalanine (F) at residue 766 (Fig. 2b). The amino acid substitution is localized in a typical SET domain that is highly conserved among diverse species (Fig. 2c; The original figure refers to Additional file 1: Figure S1).
Functional verification by allelic mutants

The mutant ebm1 was screened from our early bolting mutant lines, presenting identical phenotype with ebm3. In mutant ebm1, BraA04g017190.3 C harbored a novel $53 \mathrm{bp}$ insertion that caused the termination of amino acid coding, was previously predicted as a candidate mutant gene for early bolting in Chinese cabbage [42]. Our study revealed that mutant $e b m 3$ was caused by a $\mathrm{C}$ to $\mathrm{T}$ nonsynonymous mutation in the exon of BraA04g017190.3 C. To determine the allelism of mutant ebm1 and ebm3, they were crossed with each other. The phenotype of the hybrid was the same as that of the two mutants, which suggested that mutant $e b m 1$ and $e b m 3$ were controlled by an allelic gene. Both allelic mutations of BraA04g017190.3 C in ebm3 and ebm1 conferred the similar early bolting phenotype, which reciprocally verified the BrEBM3 function in two allelic mutants.

\section{Spatiotemporal expression of BrEBM3}

To study the relative expression levels of $B r E B M 3$ in different tissues, RNA from root, stem, leaf, bud, flower, and pod of the wild-type line 'FT' was used as a template for qRT-PCR. The data showed that BrEBM3expression was the highest in the flower, followed by the bud, leaf, and pod, with extremely low expression in the stem (Fig. 3).

\section{BrEBM3 promoter activity}

According to MutMap and cloning sequencing, the promoter sequence of BrEBM3 was not different between the mutant ebm3 and wild-type line 'FT'. Therefore, we just analyzed $B r E B M 3$ promoter activity in $A$. thaliana tissues by using the fusion vector BrEBM3 pro:GUS. Following screening based on hygromycin resistance and the GUS reporter gene, 32 independent transgenic plants were obtained. Tissues (root, stem, leaf, inflorescence, and pod) of homozygous $\mathrm{T}_{2}$ generation transgenic plants were stained in a GUS histochemical assay. Analysis of the transformed plants showed that BrEBM3 transcriptional activity was the highest in the inflorescence, followed by leaf and pod (Fig. 4). These results were in line with those of spatiotemporal expression analysis, indicating that $B r E B M 3$ expression shows a tissue-specific pattern.

Table 2 List of the candidate SNPs identified by MutMap analysis

\begin{tabular}{|c|c|c|c|c|c|c|}
\hline ID & Pos & Ref & Alt & SNP index & Variant & Description \\
\hline BraA04g005220.3 C & $3,407,432$ & G & A & 1 & nonsynonymous & CDT1-like protein b isoform X3 \\
\hline BraA04g008870.3 C & $6,258,734$ & G & $\mathrm{T}$ & 1 & nonsynonymous & LOW QUALITY PROTEIN: short-chain type dehydrogenase/reductase \\
\hline BraA04g017190.3 C & $13,129,878$ & C & $\mathrm{T}$ & 1 & nonsynonymous & histone-lysine N-methyltransferase CLF isoform X1 \\
\hline BraA04g026040.3 C & $18,591,168$ & C & $\mathrm{T}$ & 1 & nonsynonymous & LEA protein group 3 \\
\hline BraA04g031990.3 C & $21,580,928$ & C & $\mathrm{T}$ & 1 & nonsynonymous & 39 S ribosomal protein L46, mitochondrial-like \\
\hline BraA04g030150.3 C & $20,708,402$ & G & $A$ & 1 & splicing & signal recognition particle 14 kDa protein-like \\
\hline
\end{tabular}




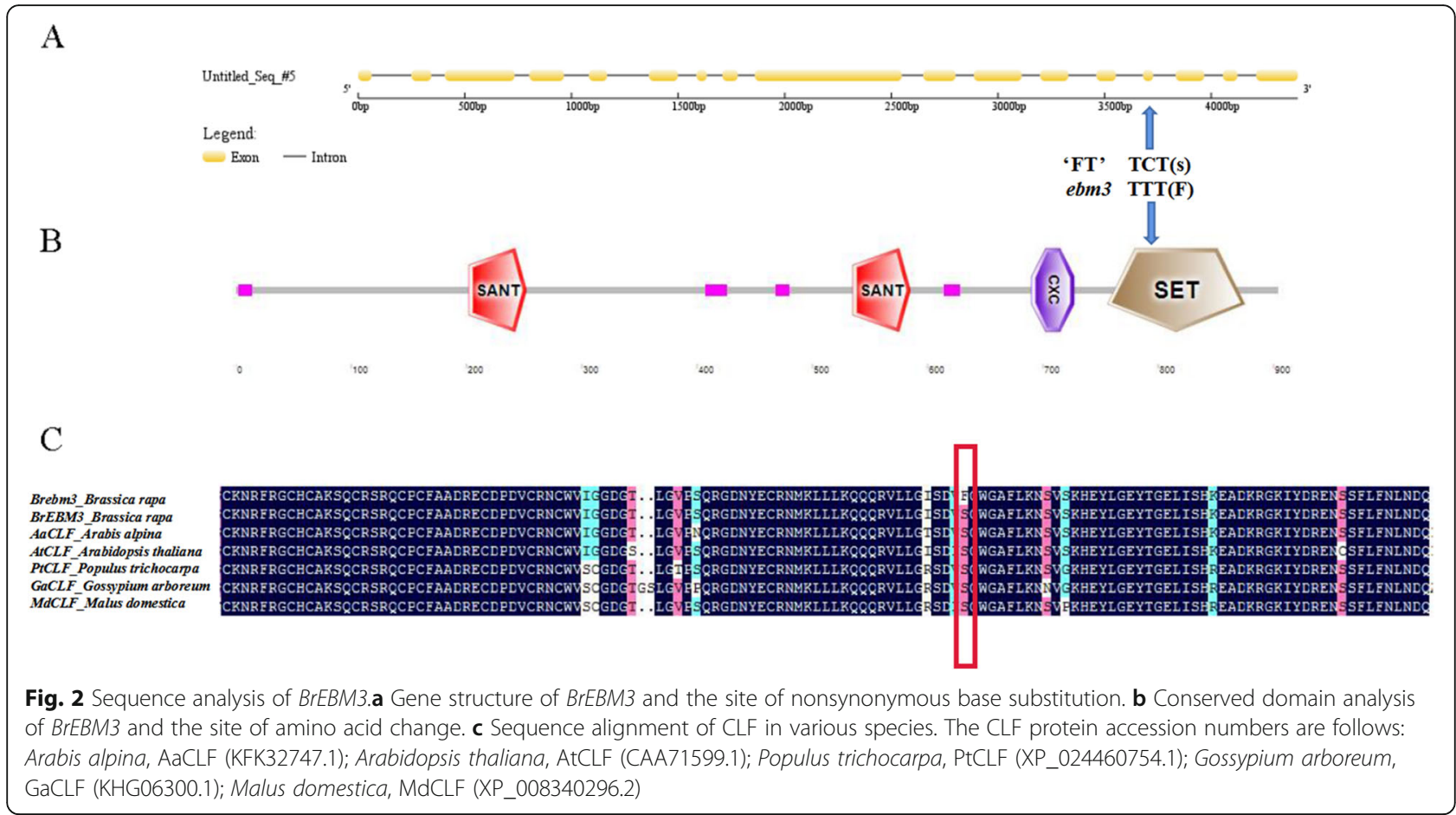

\section{BrEBM3 is located to the nucleus}

To detect the subcellular localization of BrEBM3, we constructed recombinant 35 S:GFP-BrEBM3 vector for transiently expression. Co-localization analysis of GFP and mKate fluorescent signals in the transformed Arabidopsis mesophyll cell protoplasts indicated that the fusion protein was exclusively located in the nucleus, suggesting that BrEBM3 is a nucleoprotein. And the 35 S:GFP control vector was detected within both the nucleus and cytoplasm. To prove that BrEBM3 functions at the site of the nucleus, we also expressed the $35 \mathrm{~S}$ : GFP-Brebm3 vector in Arabidopsis mesophyll cell protoplasts. Again, the fluorescent signal was strong in the nucleus. Thus, BrEBM3 is located to the nucleus (Fig. 5).

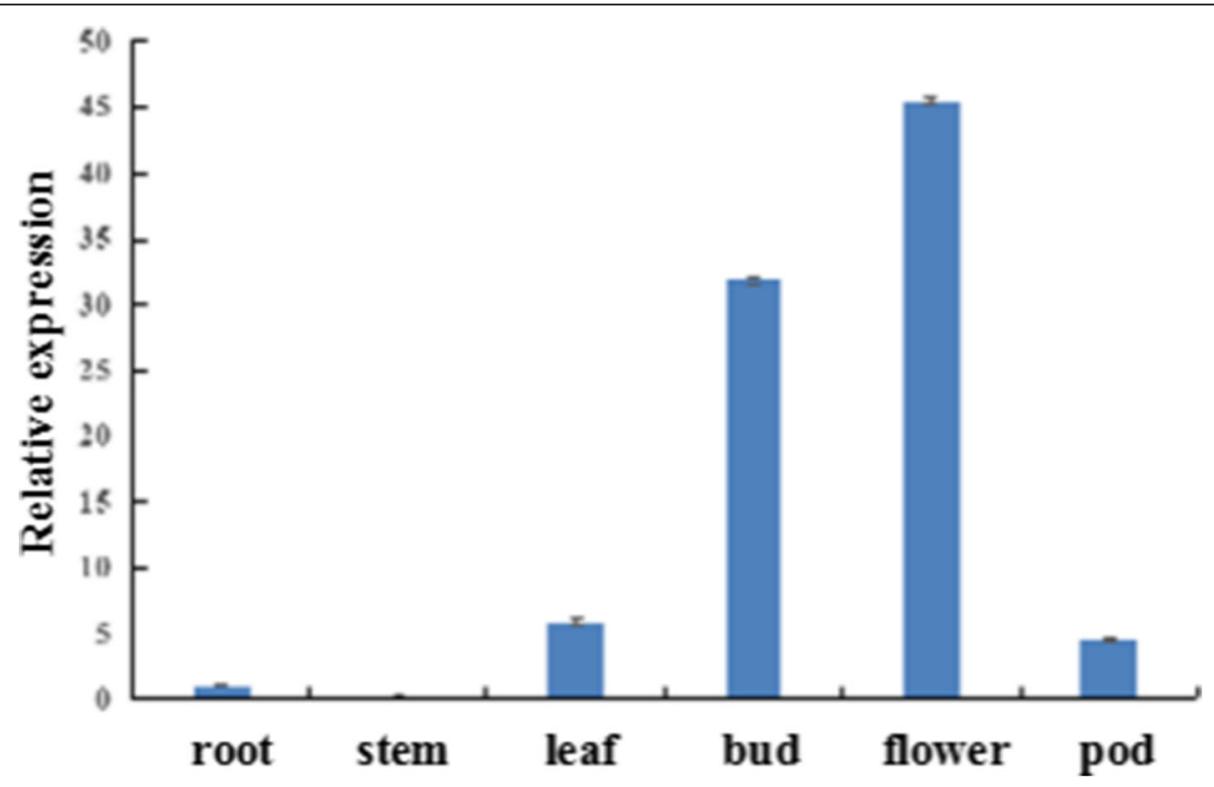

Fig. 3 Spatiotemporal expression of BrEBM3 in different tissues of the wild-type line 'FT' 


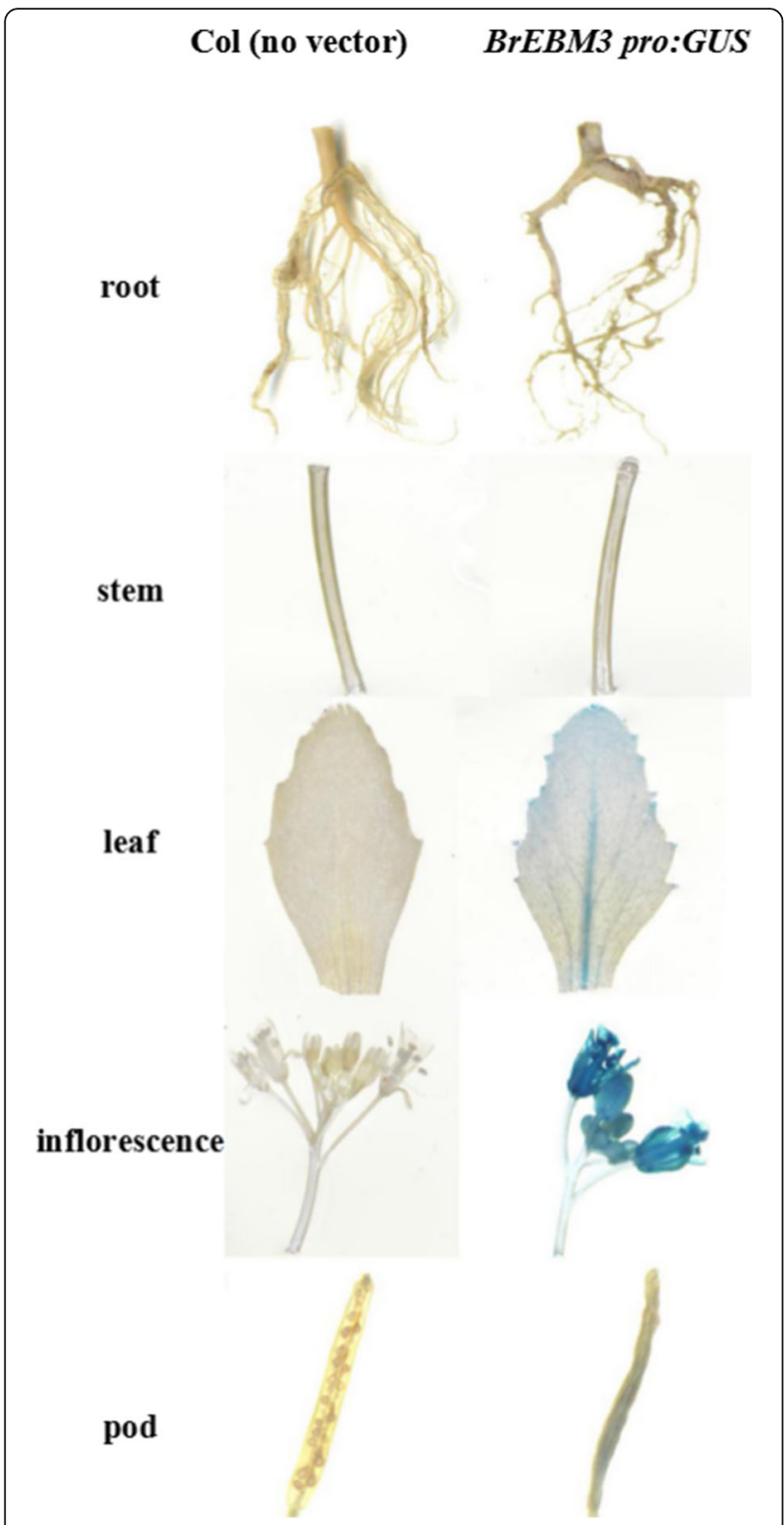

Fig. 4 GUS staining of different tissues in homozygous $T_{2^{-}}$ generation transgenic plants expressing the GUS gene under control of the $2000 \mathrm{bp}$ promoter sequence of BrEBM3. The tissues were examined under Eclipse 80i microscope (Nikon Corporation, Japan)

\section{Transcriptome profiling of the mutant ebm3}

To analyze the molecular mechanism of BrEBM3 in regulating early bolting in Chinese cabbage, a comparative transcriptome analysis of the SAM of mutant ebm3 and wild-type line 'FT' was conducted with three biological replication. After filtering and quality control, $22.32 \mathrm{~Gb}$ and 20.94 $\mathrm{Gb}$ of clean reads were obtained from the 'FT' and ebm3 library, respectively. Sufficient data were produced for each library, the sequencing quality (Q20 $\geq 99.91 \%$, Q30 $\geq 98.41 \%$ ) was sufficient, and the GC distribution (46.50-47\%) was normal (Additional file 2: Table S4). On average, 69.01 and $68.93 \%$ of clean reads from 'FT' and ebm3 libraries, respectively, were uniquely mapped to the $B$. rapa reference genome (v3.0) (Additional file 2: Table S5). In total, 1,906 DEGs, including 1,079 up- and 827 downregulated genes, were identified in the mutant ebm3 (Additional file 2: Table S6). Of the DEGs, were specifically expressed, with 81 and 79 specifically expressed in mutant ebm3 and wildtype line 'FT', respectively (Additional file 2: Table S7). To determine their biological functions, we used GO term and KEGG pathway enrichment analysis (Additional file 1: Figure S2 and Figure S3). We identified 272 significantly enriched GO terms $(p$ vaule $\leq 0.03$ ) (Additional file 2: Table S8). Of these, 163, 13, and 96 GO terms were in the biological process, cellular component and molecular function, respectively. The most significantly enriched GO terms were "regulation of transcription, DNA-templated" (GO:0006355; 193 DEGs) in biological process, "plasma membrane" (GO:0005886; 329 DEGs) in cellular component, and "transcription factor activity, sequence-specific DNA binding" (GO: $0003700 ; 184)$ in molecular function. We identified 19 significantly enriched KEGG pathways $(p$ vaule $\leq 0.03$ ) (Additional file 2: Table S8). Of these, starch and sucrose metabolism (ko00500; 76), phenylalanine metabolism (ko00940; 42), and circadian rhythm-plant (ko04712; 39) were the most significantly enriched metabolic pathway.

Flowering is an essential stage in the life cycle of higher plants and is tightly controlled by complex molecular pathways. To further explore the molecular mechanism underlying the early-bolting phenotype of the mutant ebm3, we conducted an in-depth analysis of the transcriptome data. The candidate gene BrEBM3 (BraA04g017190.3 C) was not significantly differentially expressed between the mutant ebm3 and wild-type line'FT' (Additional file 2: Table S10; Fig. 6a). The floral integrator genes FT, TSF, TFL1, and SOC1, the vernalization pathway-related genes $F L C$ and $F R I$, the ambient temperature-related gene $S V P$, the photoperiod pathway-related gene GI, age pathway-involved genes SPL3, SPL9 and SPL15, gibberellin pathway-involved genes GA20OX1-4, floral homeotic genes AG, AGL19, and FUL/AGL8 were searched in our data. CLFrepressed genes (CRGs), including SOC1 genes (BraA04g031640.3 C, BraA05g005370.3 C and BraA03g023790.3 C), two AG genes (BraA03g048590.3 C and BraA01g010430.3 C), AGL19 (BraA01g013570.3 C) were significantly upregulated in the mutant $e b m 3$ as compared to wild-type line 'FT' (Additional file 2: Table S10). We assessed BrEBM3 (BraA04g017190.3 C), FLC (BraA02g003340.3 C, BraA03g004170.3 C, BraA03g015950.3 C and BraA10g027720.3 C), and SOC1 


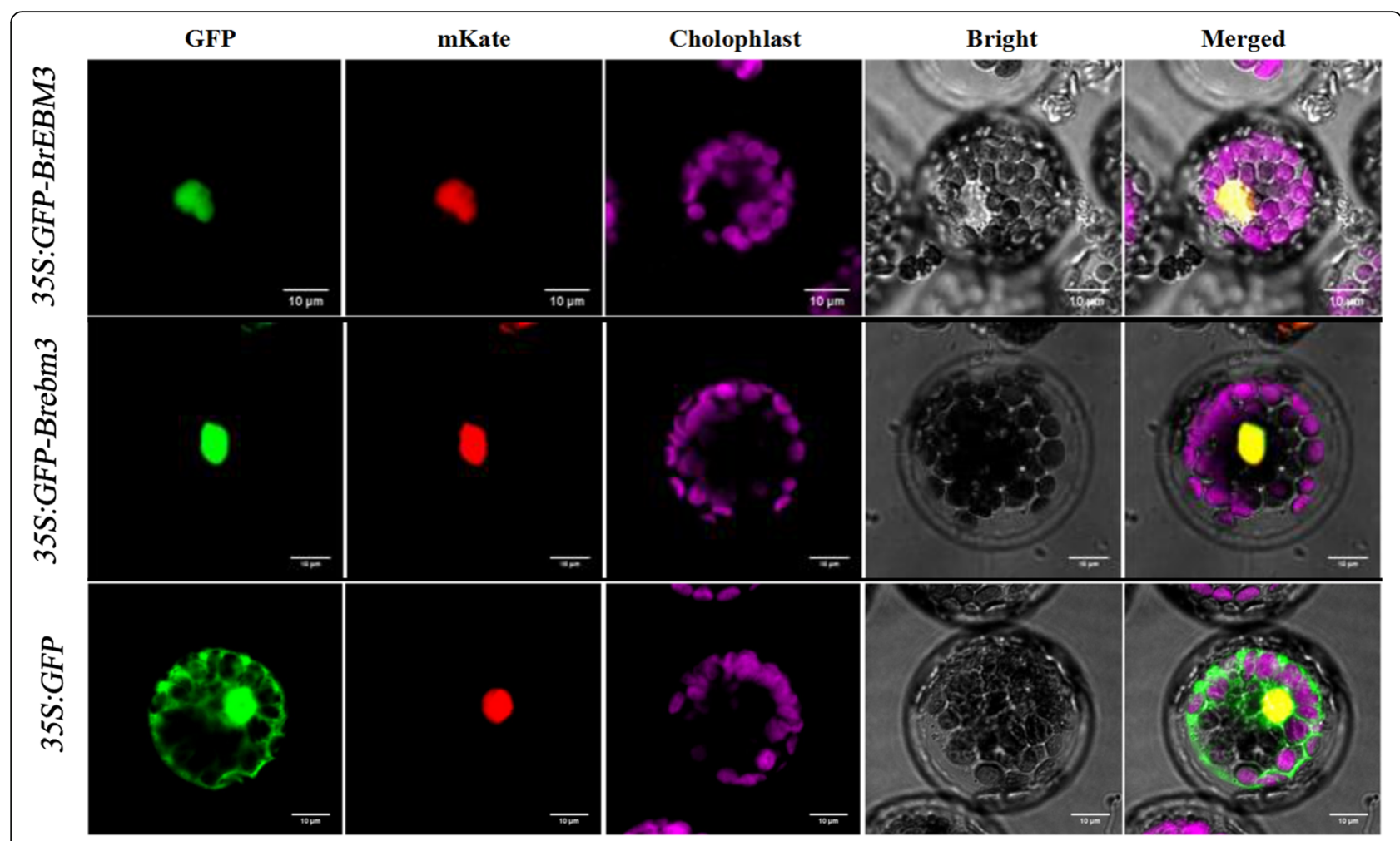

Fig. 5 Subcellular localization analysis of BrEBM3. The 35 S:GFP-BrEBM3, 35 S:GFP-Brebm3 and blank 35 S:GFP vectors were transiently expressed in Arabidopsis mesophyll cell protoplasts. The nuclear localization signal (NLS) protein fused with mKate was used as a nucleus marker. Confocal images were captured 24-48 h after inoculation and observed under a confocal laser-scanning microscope. The merged images include GFP channel (green), mKate channel (red), chloroplast autofluorescence channel (pink) and bright field. Scale bar, $10 \mu \mathrm{m}$

(BraA04g031640.3 C, BraA05g005370.3 C and BraA03g023790.3 C) expression by qRT-PCR to verify the reliability of the RNA-seq data. As described by RNA-Seq, the cDNAs from the SAM of mutant ebm3 and wild-type line 'FT' were collected with three biological replicates, respectively. The six new samples were designated as emb3-4, emb3-5, emb3-6, 'FT'-4, 'FT'-5, and 'FT'-6. As shown in Fig. 6, the expression patterns of the eight genes were generally consistent with the RNA-seq data, indicating the reliability our transcriptome analysis.

\section{Discussion}

A good understanding of the molecular mechanism of flowering time can accelerate the breeding of boltingresistant varieties [29]. To adapt to the diverse agroenvironments, vegetable crops have employed a complex and elaborate network that tightly controls flowering time. Mutants are important materials for plant functional genomics studies. The genetic basis of natural variation in flowering time has been extensively evaluated in quantitative trait loci (QTL) studies [43-46]. However, there is insufficient natural variation for effective research due to the low probability. Here, we characterized an EMS-induced early-bolting mutant, ebm3, with curled leaves, which was derived from a Chinese cabbage DH line 'FT' (Fig. 1a). The genetic background of the mutant ebm3 was relatively homozygous, and highly consistent with that of the wild-type line 'FT', which was conducive to highlight the bolting phenotype caused by the causal gene. Genetic analysis showed that the mutant trait was quality character, controlled by a single recessive nuclear gene (Table 1). Multi-season planting indicated that the early-bolting trait was genetically stable and not affected by external factors. Therefore, the mutant ebm3 is an ideal material to study important node genes in the flowering regulatory pathways in Chinese cabbage.

EMS mutagenesis has multiple advantages, such as high mutation frequency, easy screening, and stable inheritance, which is why EMS is the most widely used chemical mutagen in plants [47]. The combination of high-throughput sequencing with bulk segregant analysis (BSA) has laid the foundation for rapid mining of new genes using mutants, which has greatly facilitated functional genome studies. In our study, we used a modified MutMap method and KASP genotyping to map the candidate gene. BraA04g017190.3 C encoding histone methyltransferases CLF, was found to be responsible for the 


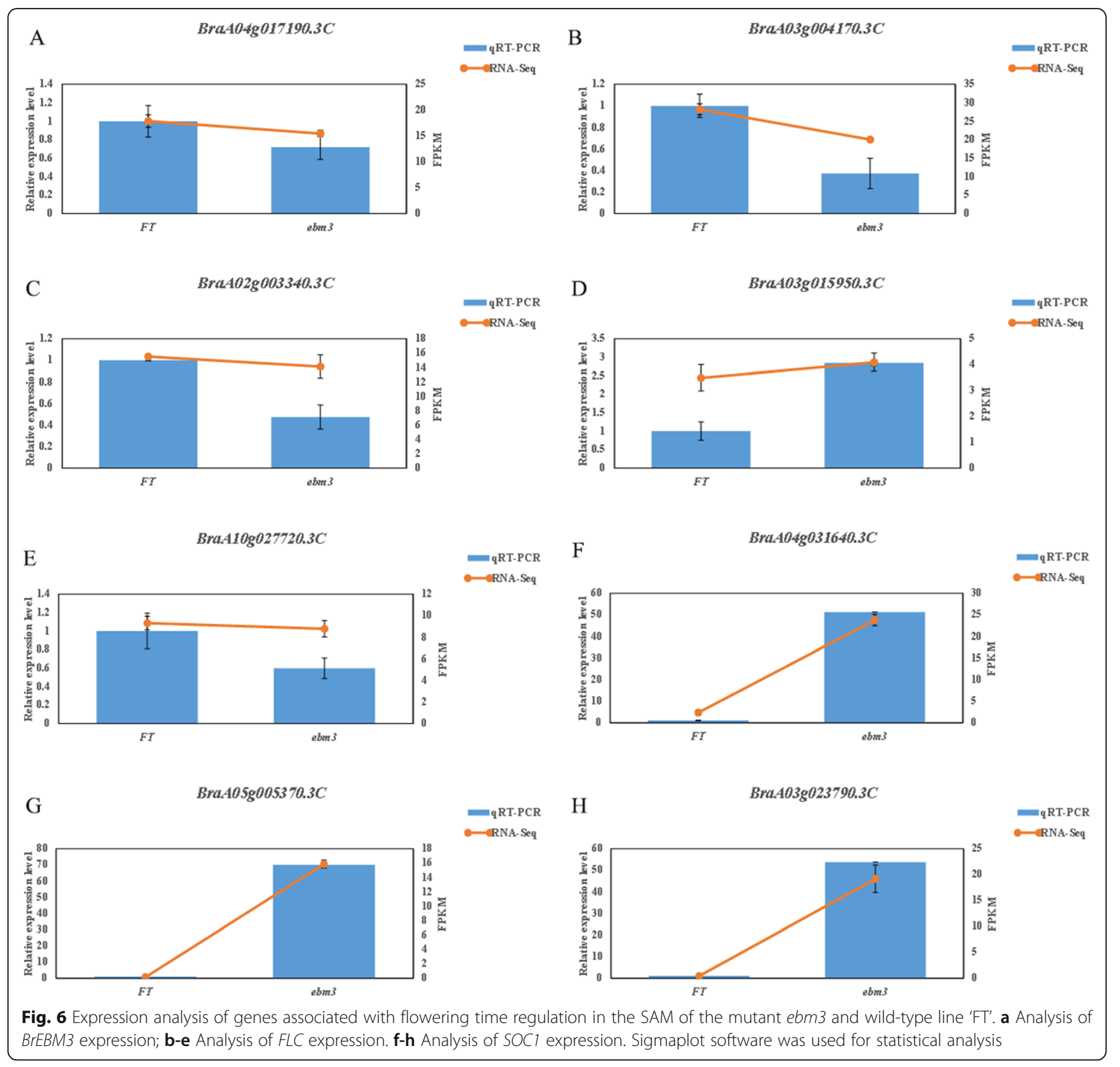

early-bolting trait (Fig. 1c-d). A nonsynonymous SNP in the 14th exon of BraA04g017190.3 C caused an amino acid substitution from $\mathrm{S}$ to $\mathrm{F}$ (Fig. 2a). Unlike loss-offunction of Arabidopsis CLF, a single amino acid change of in the Enhancer of zeste $(\mathrm{E}(\mathrm{z}))$ ortholog CLF, clf-59 retained $F L C$ repression by promoting histone $\mathrm{H} 3$ lysine 27 trimethylation (H3K27me3) deposition in FLC chromatin, causing early flowering [48]. Sequence comparison of CLF of various species revealed that the protein has a highly conserved SET domain, and the nonsynonymous SNP was located in this domain (Fig. 2b, c). The SET domain is a 130-140-amino acid evolutionarily conserved sequence motif [49]. SET domain proteins have been characterized in diverse plant species, including Arabidopsis, rice, maize, barley, grapevine, and poplar [50-55]. Most histone lysine methyltransferases (HKMTases) have a conserved SET domain, and the HKMTases with SET domain are named SET DOMAIN GROUP (SDG) proteins. Plant SDG proteins are generally divided into four classes: suppressor of protein-effect variegation 3-9 (SU(VAR)3-9); E(z); trithorax (TRX); and absent, small or homeotic disks 1 (ASH1). Detrimental effects of mutations in E(z), TRX, and ASH1 mark the importance of the SET domain in plant growth and development [56]. Moreover, SDG proteins have been suggested to affect flowering time. Mutations in five Arabidopsis SDG genes, including ASHR3/SDG2 [57], ASHH2/SDG8/EFS [58], ATX1/SDG27 [59], 
ATXR7/SDG25 [60], and CLF/SDG1 [41], cause an early-flowering phenotype, and mutations in Arabidopsis ASHH1/SDG26 [61], and three rice genes, including SDG708 [62], SDG724 [63] and SDG725 [64], confer a late-flowering phenotype. In summary, there is strong evidence that an amino acid residue substitution in the SET domain of BraA04g017190.3 C leads to the earlybolting phenotype in Chinese cabbage. Since we do not do any rescue or complementation, we can't rule out other possibilities, such as epigenetics, non-coding sequences, etc. But more importantly, allelic mutant ebm1 was screened from our early bolting mutant lines, presenting identical phenotype with ebm3. To determine the allelism of mutant ebm1 and ebm3, they were crossed with each other. The phenotype of the hybrid was the same as that of the two mutants, which suggested that mutant ebm1 and ebm3 were controlled by an allelic gene. Our study revealed that mutant ebm3 was caused by a $C$ to $\mathrm{T}$ nonsynonymous mutation in the exon of BraA04g017190.3 C. Unlike that in ebm3, the BraA04g017190.3 C in ebm1 had a novel $53 \mathrm{bp}$ insertion that caused the termination of amino acid coding. As stated above, our data revealed that BraA04g017190.3 C. is related to bolting in Chinese cabbage.

Epigenetic factors play crucial roles in flowering regulation by activating or repressing the transcription of flowering genes. Two functionally distinct multiprotein complexes of the Polycomb Group (PcG), PcG Repressive Complex 1 (PRC1) and PRC2, are the core epigenetic factors in eukaryotes [65]. PRC2 is a key repressive epigenetic mark, which maintains the repressed state of a target gene by catalyzing H3K27me3 [66]. In A. thaliana, PRC2 acts on various growth and developmental processes, including leaf morphology, floral organogenesis, cell pluripotency, vegetative-to-reproductive phase transition, and embryonic development [67-72]. In $A$. thaliana, CLF is the main component of the $\mathrm{E}(\mathrm{z})$ subunit of PRC2 [71]. Extensive evidence supports that CLF maintains suppressed expression of $F L C$ and $F T$, as well as that of several floral homeotic genes, including $A G$, AGL19, and SEP3 [41, 71, 73-77]. As a typical example of reprogramming of epigenetic states in plants, H3K27me3 repressive marks on $F L C$ can be erased by ELF6 histone demethylases during seed development [78]. A noncoding RNA transcribed from the second intron of $A G$ associated with CLF can silence $A G$ expression by mediating $\mathrm{H} 3 \mathrm{~K} 27 \mathrm{~m} 3$ deposition to form repressive chromatin [79]. The temporal-specific interaction of NF-YC and CLF mediates epigenetic regulation by derepressing $F T$ expression in photoperiod-induced flowering [6]. Loss-of-function of ASHH1/SDG26 retains SOC1/AGL2O repression by reducing H3K4me3 and H3K36me3 deposition in SOC1/AGL2O chromatin, resulting in the late-flowering phenotype [61]. A tilling mutant of (B) rapa, braA.clf-1 (Gln615Stop), displayed small plant size, altered floral development, and curled leaves due to reduced H3K27me3 and high expression levels of floral homeotic genes such as $A G$ and $A G L$ loci [80]. In the present study, RNA-Seq data revealed that $A G$ and $A G L$ loci, e.g., SOC1/AGL20 and AGL19, were significantly upregulated in the mutant ebm3 (Additional file 2: Table S10). Therefore, it is reasonable to speculate that mutation in BrEBM3 mediates reduced H2K27me3 deposition and high expression of the $A G$ and $A G L$ loci in Chinese cabbage. Hereafter, to determined significant enrichment of H3K27me3 epigenetic marks at genomewide levels, chromatin immunoprecipitation, followed by sequencing (ChIP-seq) assays should be developed from the SAM of the mutant ebm3. The data from ChIP-seq can strengthen the information generated from our RNA-Seq to H3K27me3 levels at CRGs, e.g., $A G$ and $A G L$ loci. In addition, the H3K27me3 levels of the CRGs should be verified by locus-specific PCR on ChIPderived DNA-materials (ChIP-PCR) [81].

\section{Conclusions}

The transition to flowering is an essential developmental stage in the plant life cycle. Plants need to flowering in the most favorable conditions to ensure maximal reproductive success. Timely flowering is conducive to crop production, harvesting, and marketing. In this study, based on MutMap sequencing, KASP genotyping, and allelism test, $B r E B M 3$, encoding the histone methyltransferase CLF, was determined to control the early-bolting trait in Chinese cabbage. BrEBM3 was highly expressed in the floral organs, and the translation product localized in the nucleus. Transcriptome profiling was conducted to identify potential CLF-repressed genes in mutant ebm3. Collectively, our findings will be invaluable for understanding the molecular mechanism of flowering time in Chinese cabbage.

\section{Methods \\ Plant materials}

The Chinese cabbage DH line 'FT' was used as a wildtype line in this study propagated from Chinese cabbage variety 'Fukuda 50', which was screened by Shenyang greenstar Chinese cabbage research institute (Shenyang, China) [82]. An early-bolting mutant with stable inheritance was obtained from 'FT' seeds by multigenerational screening after EMS mutagenesis, and was designated ebm3. The mutant generation method has been described in detail in Fu et al. [83]. All plants were raised in the greenhouse of Shenyang Agricultural University.

A. thaliana ecotype Columbia-0 (Col-0) was obtained from the Arabidopsis Biological Resource Center (ABRC; http://abrc.osu.edu) and preserved by the Liaoning Key Laboratory of Genetics and Breeding for Cruciferous 
Vegetable Crops at Shenyang Agricultural University. All Arabidopsis plants were grown in a growth chamber at Shenyang Agricultural University. Culture conditions were as described by Wang et al. [84].

\section{Genetic analysis}

To study the inheritance characteristics, the mutant ebm3 and wild-type line 'FT' were used as parents. An $F_{1}$ generation obtained by a reciprocal cross was selfcrossed to obtain an $F_{2}$ segregating generation. The $F_{1}$ generation was backcrossed with both parents to obtain a $\mathrm{BC}_{1}$ population. The segregation ratios of the $\mathrm{F}_{2}$ and $\mathrm{BC}_{1}$ populations were analyzed using the chi-square test. The $F_{2}$ population was also used for mutant gene identification and genotyping. Individual plants were grown in a greenhouse at Shenyang Agricultural University.

\section{Allelism test between the ebm 1 and ebm 3 mutants}

A early bolting mutant $e b m 1$ presenting identical phenotypes, was likewise derived from EMS mutagenesis of 'FT' seeds. To determine the early bolting traits of the two mutants from the allelic gene mutation, the mutants were reciprocally crossed.

\section{Evaluation of bolting characteristics}

Three bolting characteristics were measured, i.e., SP, DE, and FT, as previously reported by $\mathrm{Yu}$ et al. [85]. Thirty mutant ebm3 plants (10 individuals per replication, with three replicates each) were selected for a survey of bolting characteristics in comparison with wild-type line 'FT' under natural conditions in the autumn of 2017.

\section{Candidate SNP identification by the MutMap method}

A modified MutMap method was used to identify the candidate gene for the mutant ebm3. DNA was extracted from $15 \mathrm{~F}_{2}$ individuals with the early-bolting phenotype and the parental lines using a DNAsecure Plant Kit (Tiangen Biotech Co., Ltd., Beijing, China) according to the manufacturer's instructions. Equal amounts of each DNA from the $15 \mathrm{~F}_{2}$ individuals were mixed to construct an offspring pool. Sequencing libraries of the mutant ebm3 (ebm3), wild-type line 'FT' ('FT'), and offspring pool $\left(\mathrm{F}_{2}\right.$ ebm3) were generated using a TruSeq Nano DNA HT Sample preparation Kit (Illumina, San Diego, CA, USA). The libraries were sequenced using Illumina HiSeq ${ }^{\mathrm{TM}}$ PE150 (Novogene Co., Ltd., Beijing, China). After quality control and filtration, the clean reads of each sample were aligned to the $B$. rapa reference genome (http://brassicadb.org/brad/, v3.0) using BurrowsWheeler Alignment tool (BWA) [86]. Alignment files were converted to BAM files using the SAMtools software [87]. SNP calling was performed using GATK [88] and annotated using ANNOVAR [89]. The screened SNPs between the $M$ and $W$ library were used to calculate the SNP index in offspring-pool library. The sliding window method was used to determine the SNP index of the whole genome in offspring pool library.

\section{SNP genotyping by KASP}

To verify the real existence of the candidate SNP, a sequence surrounding the locus was amplified using DNA from the mutant ebm3 and wild-type line 'FT' and the primer pair 5'-ATACTTTGCTTTGGTTGACTCTAC$3^{\prime}$ and 5' ${ }^{\prime}$-TCGTGTTTACTTACACTGTTCTGT-3'. Purified PCR product was ligated into the PMD 18-T Vector (Takara Biotech Co., Ltd., Dalian, China), and transformed into TOP10 competent cells (ComWin Biotech Co., Ltd., Beijing, China). The recombinant plasmid was sequenced by Sanger sequencing (Genewiz lnc., Tianjin, China). Sequence alignment was performed using the SeqMan software.

The candidate SNP was confirmed using a KASP assay to detect whether the locus co-segregated with the mutant phenotype. For KASP genotyping, DNA from 200 $\mathrm{F}_{2}$ individuals with the early-bolting phenotype was used. Two allele-specific primers carrying the fluorescence probes FAM and HEX and the candidate SNP at the 3' end (Primer_AlleleFAM: AGGTTTTACTTGGAATAT CTGATGTATC; Primer_AlleleHEX: CAGGTTTTAC TTGGAATATCTGATGTATT), and a common genome-specific primer (Primer_Common: GTTACG CATCTACTATACCTTTAGGAAAG), were designed following standard KASP guidelines of the laboratory of the Government Chemist (LGC http://www. lgcgenomics.com/). The primer mixture was prepared as recommended by LGC Genomics. PCR mixture preparation and cycling were conducted as described by $\mathrm{Xi}$ et al. [34]. Fluorescence data were read using a 7900HT Fast Real-Time PCR System (Applied Biosystems, Foster City, CA, USA).

\section{Quantitative reverse transcription-PCR (qRT-PCR)}

Total RNA of each sample was extracted using TRIzol Reagent (Invitrogen, Carlsbad, CA, USA). First-strand cDNA was synthesized using FastKing gDNA Dispelling RT SuperMix (Tiangen Biotech Co., Ltd., Beijing, China). The reaction system was performed with UltraSYBR Mixture (ComWin Biotech Co., Ltd., Beijing, China). PCR amplification was run in a QuantStudio ${ }^{\text {ta }} 6$ Flex Real-Time PCR System (Applied Biosystems, Carlsbad, CA, USA). The Actin gene was selected as an internal control. Relative gene expression data were calculated by the $2^{-\triangle \Delta \mathrm{Ct}}$ method [90]. The data were analyzed using the QuantStudio ${ }^{\text {Tu }} 6$ Flex Manager software. Three technical and biological replicates were included for each sample. The qRT-PCR primer pairs were listed in Additional file 2: Table S11. 


\section{Promoter activity assay}

The promoter sequence (2,000 bp upstream of the initiation codon) of BrEBM3 was amplified from DNA of the wild-type line 'FT', using the primer pair 5'ccgggatccTCTAGAgcgaagccaagtagtaagcact- $3^{\prime}$ and $5^{\prime}$ gcaggtcgacTCTAGAtgtcgaggagccagatcgga-3' (uppercase letters indicate an $\mathrm{XbaI}$ site). The amplification product was digested with $\mathrm{XbaI}$ and ligated into the pC1301IgT vector containing fused GUS reporter gene. The recombinant plasmid was introduced into Agrobacterium tumefaciens strain GV3103. A. tumefaciens-mediated transformation was used to transfer the BrEBM3 pro: GUS vector into $A$. thaliana Col-0 by the floral dip method. Transgenic plants were screened on $0.5 \times$ Murashige and Skoog (MS) medium containing $0.25 \mathrm{mg} \mathrm{L}^{-1}$ hygromycin. The GUS reporter gene was amplified from DNA of all hygromycin-resistant plants, using the primer pair 5' - AACCACAAACCGTTCTACTTTACTG3' and 5'-TACATTACAAGACGCTGCGAGT-3'. A GUS histochemical assay was performed on various tissues (root, stem, leaf, inflorescence and pod) of the transgenic plants [91].

\section{Subcellular localization}

The full-length $B r E B M 3$ and its allele Brebm 3 coding sequence without the stop codon was amplified from cDNA of the wild-type line 'FT', using the primer pair $5^{\prime}$ - cgatCACCTGCaaaacaacatggcgtcgggagcttcgcc-3' and 5' -cagtCACCTGCaaaatacaagcaaccttcttgggtctac-3' (uppercase letters indicate an AarI site). The amplification product was digested with AatI and inserted into the pBWA(V)HS-ccdb-GLosgfp vector, resulting in an Nterminal fusion vector with GFP under the control of the CaMV35S promoter (35 S:GFP-BrEBM3 and 35 S: GFP-Brebm3). The 35 S:GFP vector was used as a control. The constructs were respectively transiently transformed into A. thaliana mesophyll cell protoplasts, as described by Wang et al. [84]. The pBWA(V)HS-NLSmKATE vector was served as a nucleus marker. Fluorescence data were obtained by confocal laser-scanning microscope (Leica TCS SP8, Wetzlar, Germany).Excitation wavelengths used were $488 \mathrm{~nm}$ for GFP and $561 \mathrm{~nm}$ for mKate. Emission wavelengths were $507 \mathrm{~nm}$ for GFP and $580 \mathrm{~nm}$ for mKate.

\section{Transcriptome profiling}

When the mutant ebm3 reached the critical point of bolting, the SAM of three mutant and three wild-type line 'FT' was randomly selected and mixed; the mixed samples were used as one biological replicates. Three independent biological replicates of mutant and wild-type line 'FT' were used, respectively. Total RNA of the six samples (emb3-1, emb3-2, emb3-3, 'FT'-1, 'FT'-2, and 'FT'-3) was extracted using TRIzol Reagent (Invitrogen,
Carlsbad, CA, USA). RNA quantity and purity was analyzed using a Bioanalyzer 2100 and RNA 6000 Nano LabChip Kit (Agilent Technologies, Santa Additional file 2: Clara, CA, USA). Following purification and fragmentation, the cleaved RNA fragments were reversetranscribed to create cDNA libraries using a mRNASeqsample preparation kit (Illumina, San Diego, CA, USA). The libraries were paired-end sequenced using an Illumina HiSeq 4000 platform (LC-Bio Technology Co., Ltd., Hangzhou, China). Following quality control and filtration, the clean reads were aligned to the $B$. rapa reference genome (v3.0) using HISAT. StringTie was used to assemble the alignments into transcripts and to compute transcript abundance by calculating Fragments Per Kilobase of transcript per Million mapped reads (FPKM). Differentially expressed genes (DEGs) were defined based on $\mid \log _{2}$ (fold change) $\mid \geq 1$ and $p<0.05$, using the $\mathrm{R}$ package Ballgown [92]. Functional analysis of the DEGs included Gene Ontology (GO) and Kyoto Encyclopedia of Genes and Genomes (KEGG) pathway analyses [93, 94].

\section{Sequence characteristic analyses}

The gene structure was displayed using the Gene Structure Display Server (http://gsds.cbi.pku.edu.cn/). Physical and chemical characteristics were predicted using Protparam (http://web.expasy.org/protparam). Domains were identified and annotated using Simple Modular Architecture Research Tool (http://smart.embl-heidelberg.de/).

\section{Abbreviations}

CLF: CURLF LEAF; DEG: Differentially expressed genes; DH: Doubled haploid; EMS: Ethyl methanesulgonate; FPKM: Fragments Per Kilobase of transcript per Million mapped reads; GO: Gene Ontology; KASP: Kompetitive allele-specific polymerase chain reaction; KEGG: Kyoto Encyclopedia of Genes and Genomes; qRT-PCR: Quantitative reverse transcription-PCR; SAM: Shoot apical meristem; SET: Suppressor of protein-effect variegation 3-9, Enhancer-ofzeste, Trithorax; SNP: Single-nucleotide polymorphism; WGT: Whole genome triplication

\section{Supplementary Information}

The online version contains supplementary material available at https://doi. org/10.1186/s12870-021-03153-9.

\footnotetext{
Additional file 1: Figure S1. Original figure of CLF sequence alignment in various species. The red line inner part is the cropping part in Fig. $2 \mathrm{C}$. Figure S2. GO enrichment analysis of DEGs obtained in the SAM of mutant ebm3 and wild-type line 'FT' by transcriptome profiling. Figure S3. Pathway enrichment analysis of DEGs obtained in the SAM of mutant ebm3 and wild-type line 'FT' by transcriptome profiling.

Additional file 2: Table S1. Summary of sequencing data quality by MutMap analysis. Table S2. Summary of sequencing depth and coverage statistics by MutMap analysis. Table S3. Genotyping results of the six SNPs $(3,407,432,6,258,734,13,129,878,18,591,168,20,708,40$ and $21,580,928)$. Table S4. Summary of sequencing data quality by transcriptome profiling. Table S5. Summary of read statistics by transcriptome profiling. Table S6. List of 1,906 DEGs identified by transcriptome profiling. Table S7. List of specifically expressed genes
} 
identified by transcriptome profiling. Table S8. List of significantly enriched GO terms identified by transcriptome profiling. Table S9. List of significantly enriched KEGG metabolic pathways. Table S10. Information on genes associated with flowering time regulation identified by transcriptome profiling. Table S11. Primers used for qRT-PCR.

\section{Acknowledgements}

We thank Editage (www.editage.cn) for English language editing.

\section{Authors' contributions}

$C T$ and JR analyzed the data and drafted the manuscript. LW, WF, JZ, and $M Q$ participated in the creation of materials and performed the experiments. $X Y, H F$ and $Z L$ directed the whole study including designing experiments and revising the manuscript. All authors have read and approved the final manuscript.

\section{Funding}

This work was supported by grants from the National Natural Science Foundation of China (No.31772298). The funding played roles in the design of the study and collection, analysis, and interpretation of data.

\section{Availability of data and materials}

The datasets supporting the conclusions of this article are included within the article and its additional files. The Illumina RNA-Seq datasets are available in the Sequence Read Archives (SRA) of the National Center for Biotechnology Information (NCBI) under the accession number SRR15152892, SRR15152891, SRR15152890, SRR15152889, SRR15152888, SRR15152887 of the Bioproject ID PRJNA746103. The DNA resequencing datasets are available in the SRA under accession number SRR15174648, SRR15174649, SRR15174650 of the Bioproject ID PRJNA746415. Genomic sequences and gene annotation information of B.rapa are downloaded online at http://brassicadb.cn.

\section{Declarations}

Ethics approval and consent to participate Not applicable.

\section{Consent for publication}

Not applicable.

\section{Competing interests}

All the authors declare that they have no competing interests.

Received: 2 October 2020 Accepted: 2 August 2021

Published online: 13 August 2021

\section{References}

1. Bloomer RH, Dean C. Fine-tuning timing: natural variation informs the mechanistic basis of the switch to flowering in Arabidopsis thaliana. J Exp Bot. 2017;68(20):5439-52

2. Shea DJ, Itanashi E, Takada S, Fukai E, Kakizaki T, Fujimoto R, Okazaki K. The role of FLOWERING LOCUS C in vernalization of Brassica: the importance of vernalization research in the face of climate change. Crop Pasture Sci. 2018; 69(1):30-9.

3. Cho LH, Yoon J, An G. The control of flowering time by environment factors. Plant J. 2017:90(4):708-19.

4. Fornara F, de Montaigu A, Coupland G. SnapShot. Control of flowering in Arabidopsis. Cell. 2010;141(3):550,550.e1-2.

5. Perrella G, Vellutini E, Zioutopoulou A, Patitaki E, Headland LR, Kaiserli E. Let it bloom: cross-talk between light and flowering signaling in Arabidopsis. Physiol Plant. 2020;169(3):301-11.

6. Liu X, Yang YH, Hu YL, Zhou LM, Li YG, Hou XL. Temporal-Specific interaction of NF-YC and CURLF LEAF during the floral Transition regulation flowering. Plant Physiol. 2018;177(1):105-14.

7. Abe M, Kobayashi Y, Yamamoto S, Daimon Y, Yamaguchi A, Ikeda $Y$ Ichimoki H, Notaguchi M, Goto K, Araki T. FD, a bZIP protein mediating signals from the floral pathway integrator FT at the shoot apex. Sicence. 2005;309(5737):1052-6.
8. Leijten W, Koes R, Roobeek I, Frugis G. Translating flowering time from Arabidopsis thaliana to Brassicaceae and Asteraceae crop species. Plants (Basel). 2018;7(4):111.

9. Castillejo C, Pelaz S. The balance between CONSTANS and TEMPRANILLO activities determines FT expression to trigger flowering. Curr Biol. 2008;18(17):1338-43.

10. Sawa M, Nusinow DA, Kay SA, Imaizumi T. FKF1 and GIGANTEA complex formation is required for day-length measurement in Arabidopsis. Science. 2007;318(5848):261-5

11. Fujiwara S, Oda A, Yoshida R, Niinuma K, Miyata K, Tomozoe Y, Tajima T, Nakagawa M, Hauashi K, Coupland G, Mizoguchi T. Circadian clock proteins LHY and CCA1 regulate SVP protein accumulation to control flowering in Arabidopsis. Plant Cell. 2008;20(11):2960-71.

12. Searle I, He YH, Turck F, Vincent C, Fornara F, Kröber S, Amasino RA, Coupland G. The transcription factor FLC confers a flowering response to vernalization by repressing meristem competence and systemic signaling in Arabidposis. Genes Dev. 2006;20(7):898-912.

13. Johanson U, Weat J, Lister S, Michaels S, Amasino R, Dean C. Molecular analysis of FRIGIDA, a major determinant of natural variation in Arabidopsis flowering time. Science. 2000;290(5490):344-7.

14. Kim DH, Sung S. Accelerated vernalization response by an altered PHDfinger protein in Arabidopsis. Plant Signal Behav. 2017:12(5):e1308619.

15. Csorba T, Questa JI, Sun QW, Dean C. Antisense COOLAIR mediates the coordinated switching of chromatin states at FLC during vernalization. Proc Natl Acad Sci U S A. 2014;111(45):16160-5.

16. Kim DH, Xi YP, Sung S. Modular function of long noncoding RNA, COLDAIR, in the vernalization response. PLoS Genet. 2017;13(7):e1006939.

17. Gu XF, Le C, Wang YZ, Li ZC, Jiang DH, Wang YQ, He YH. Arabidopsis FLC clade members form flowering-repressor complexes coordinating responses to endogenous and environment cues. Nat Commun. 2013;4:1947.

18. Schönrock N, Bouveret R, Leroy O, Borghi L, Köhler C, Gruissem W, Hennig L. Polycomb-group protein repress the floral activator AGL19 in the FLCindependent vernalization pathway. Genes Dev. 2006:15(12):1667-78.

19. Wu G, Park MY, Conway SR, Wang JW, Weigel D, Poethig RS. The sequential action of miR156 and miR172 regulates developmental timing in Arabidopsis. Cell. 2009;138(4):750-9.

20. Yant L, Mathieu J, Dinh T, Ott F, Lanz C, Wollmann H, Chen X, Schmid M. Orchestration of the floral transition and floral development in Arabidopsis by the bifunctional transcription factor APETALA2. Plant Cell. 2010;22(7): 2156-70.

21. Ito T, Okada K, Fukazawa J, Takahashi Y. DELLA-dependent and -independent gibberellin signaling. Plant Signal Behav. 2018;13(3):e1445933.

22. Lee JH, Yoo SJ, Park SH, Hwang I, Lee JS, Ahn JH. Role of SVP in the control of flowering time by ambient temperature in Arabidopsis. Genes Dev. 2007; 21(4):397-402.

23. Wang XW, Wang HZ, Wang J, Sun RF, Wu J, Liu SY, Bai YQ, Mun JH, Bancroft I, Cheng F, Huang S, Li X, Hua W, Wang J, Wang X, Freeling M, Pires JC, Paterson AH, Chalhoub B, Wang B, Hayward A, Sharpe AG, Park BS, Weisshaar B, Liu B, Li B, Liu B, Tong C, Song C, Duran C, Peng C, Geng C, Koh C, Lin C, Edwards D, Mu D, Shen D, Soumpourou E, Li F, Fraser F, Conant G, Lassalle G, King GJ, Bonnema G, Tang H, Wang H, Belcram H, Zhou H, Hirakawa H, Abe H, Guo H, Wang H, Jin H, Parkin IA, Batley J, Kim JS, Just J, Li J, Xu J, Deng J, Kim JA, Li J, Yu J, Meng J, Wang J, Min J, Poulain J, Wang J, Hatakeyama K, Wu K, Wang L, Fang L, Trick M, Links MG, Zhao M, Jin M, Ramchiary N, Drou N, Berkman PJ, Cai Q, Huang Q, Li R, Tabata S, Cheng S, Zhang S, Zhang S, Huang S, Sato S, Sun S, Kwon SJ, Choi SR, Lee TH, Fan W, Zhao X, Tan X, Xu X, Wang Y, Qiu Y, Yin Y, Li Y, Du Y, Liao Y, Lim $Y$, Narusaka $Y$, Wang $Y$, Wang Z, Li Z, Wang Z, Xiong Z, Zhang Z, Brassica rapa Genome Sequencing Project Consortium. The genome of the mesopolyploid crop species Brassica rapa. Nat Genet. 2011;43(10):1035-9.

24. Zhang XM, Meng L, Liu B, Hu YY, Cheng F, Liang JL, Aarts MGM, Wang XW, Wu J. A transposon insertion in FLOWERING LOCUS T is associated with delayed flowering in Brassica rapa. Plant Sci. 2015;241:211-20.

25. Franks SJ, Perez-Sweenry B, Strahl M, Nowogrodzki A, Weber JJ, Lalchan R, Jordan KP, Litt A. Variation in the flowering time orthologs BrFLC and BrSOC1 in a natural population of Brassica rapa. PeerJ. 2015;3:e1339.

26. Hong JK, Kim SY, Kim KS, Kwon SJ, Kim JS, Kim JA, Lee SI, Lee YH. Overexpression of a Brassica rapa MADS-box gene, BrAGL20, induces early flowering time phenotypes in Brassica napus. Plant Biotechnol Rep. 2013:7(3):231-7.

27. Schranz ME, Quijada P, Sung SB, Lukens L, Amasino R, Osborn TC. Characterization and effects of the replicated flowering time gene FLC in Brassica rapa. Genetics. 2002;162(3):1457-68. 
28. Kim JS, Chung TY, King GJ, Jin M, Yang TJ, Jin YM, Kim HL, Park BS. A sequence-tagged linkage map of Brassica rapa. Genetics. 2006;174(1):29-39.

29. Takada S, Akter A, Itabashi E, Nishida N, Shea DJ, Miyaji N, Mehraj H, Osabe K, Shimizu M, Takasaki-Yasuda T, Kakizaki T, Okazaki K, Dennis ES, Fujimoto R. The role of FRIGIDA and FLOWERING LOCUS C genes in flowering time of Brassica rapa leafy vegetables. Sci Rep. 2019;9(1):13843.

30. Wu J, Wei KY, Cheng F, Li SK, Wang Q, Zhao JJ, Bonnema G, Wang XW. A naturally occurring InDel variation in BraA.FLC.b (BrFLC2) associated with flowering time variation in Brassica rapa. BMC Plant Biol. 2012;12:151.

31. Xiao D, Zhao JJ, Hou XL, Basnet RK, Carpio DPD, Zhang NW, Bucher J, Lin K, Cheng F, Wang XW, Bonnema G. The Brassica rapa FLC homologue FLC2 is a key regulator of flowering time, identified through transcriptional coexpression networks. J Exp Bot. 2013;64(14):4503-16.

32. Yuan $Y X$, Wu J, Sun RF, Zhang XW, Xu DH, Bonnema G, Wang XW. A naturally occurring splicing site mutation in the Brassica rapa $\mathrm{FLCl}$ gene is associated with variation in flowering time. J Exp Bot. 2009;60(4):1299-308

33. Zhao JJ, Kulkarni V, Liu NN, Carpio DPD, Bucher J, Bonnema G. BrFLC2 (FLOWERING LOCUS C) as a candidate gene for a vernalization response QTL in Brassica rapa. J Exp Bot. 2010;61(6):1817-25.

34. Xi X, Wei KY, Gao BZ, Liu JH, Liang JL, Cheng F, Wang XW, Wu J. BrFLC5: a weak regulator of flowering time in Brassica rapa. Theor Appl Genet. 2018; 131(10):2107-16.

35. Duan WK, Zhang HJ, Zhang B, Wu XT, Shao SX, Li Y, Hou XL, Liu TK. Role of vernalization-mediated demethylation in the floral transition of Brassica rapa. Planta. 2017;245(1):227-33.

36. Huang FY, Liu TK, Hou XL. Isolation and functional characterization of a floral repressor, BCMAF1, from Pak-choi (Brassica rapa ssp. Chinensis). Front Plant Sci. 2018:9:290.

37. Huang FY, Liu TK, Tang J, Duan WK, Hou XL. BcMAF2 activates BCTEM1 and represses flowering in Pak-choi (Brassica rapa ssp. chinensis). Plant Mol Biol. 2019;100(1-2):19-32.

38. Xie QG, Lou P, Hermand V, Aman R, Park HJ, Yun DJ, Kim WY, Salmela MJ, Ewers BE, Weinig C, Khan SL, Schaible DLP, McClung CR. Allelic polymorphism of GIGANTEA is responsible for naturally occurring variation in circadian period in Brassica rapa. Proc Natl Acad Sci U S A. 2015;112(12): 3829-34.

39. Su TB, Wang WH, Li PR, Zhang B, Li P, Xin XY, Sun HH, Yu YJ, Zhang DS, Zhao XY, Wen CL, Zhou G, Wang YT, Zheng HK, Yu SC, Zhang FL. A genomic variation map provides insights into the genetic basis of spring Chinese cabbage (Brassica rapa ssp. pekinensis) selection. Mol Plant. 2018; 11(11):1360-76.

40. Abe A, Kosugi S, Yoshida K, Natsume S, Takagi H, Kanzaki H, Matsumura H, Yoshida K, Mitsuoka C, Tamiru M, Innan H, Cano L, Kamoun S, Terauchi R. Genome sequencing reveals agronomically important loci in rice using MutMap. Nat Biotechnol. 2012;30(2):174-8.

41. Goodrich J, Puangsomlee P, Martin M, Long D, Meyerowitz EM, Coupland G. A Polycomb-group gene regulates homeotic gene expression in Arabidopsis. Nature. 1997;386(6620):44-51.

42. Huang S, Hou L, Fu W, Liu Z, Li C, Li X, Feng H. An insertion mutation in Bra032169 encoding a histone methyltransferase is responsible for early bolting in Chinese cabbage (Brassica rapa L. ssp. pekinensis). Front Plant Sci. 2020;11:547

43. Brachi B, Faure N, Horton M, Flahauw E, Vazquez A, Nordborg M, Bergelson J, Cuguen J, Roux F. Linkage and association mapping of Arabidopsis thaliana flowering time in nature. PLoS Genet. 2010;6(5):e1000940.

44. Long Y, Shi J, Qiu D, Li R, Zhang C, Wang J, Hou J, Zhao J, Shi L, Park BeonSeok, Choi SR, Lim YP, Meng J. Flowering time quantitative trait loci analysis of oilseed Brassica in multiple environments and genomewide alignment with Arabidopsis. Genetics. 2007:177(4):2433-44.

45. Luo ZL, Wang M, Long Y, Huang YJ, Shi L, Zhang CY, LiuY, Fitt BDL, Xiang JX, Mason AS, Snowdon RJ, Liu PF, Meng JL, Zou J. Incorporating pleiotropic quantitative trait loci in dissection of c8omplex traits: Seed yield in rapeseed as an example. Theor Appl Genet. 2017;130(8):1569-85

46. Wang YG, Wang XS, Wang $X$, Zhao QN, Lv XX, Feng $H$. Construction of chromosome segment substitution lines of Chinese cabbage (Brassica rapa L. ssp. pekinensis) in the background of $\mathrm{RcBr}$ (B. rapa L. ssp. dichotoma) and characterization of segments representing the bolting trait. Mol Breeding. 2018:38(4):35.

47. Brockman HE, de Serres FJ, Ong TM, DeMarini DM, Katz AJ, Griffiths AJ, Stafford RS. Mutation tests in Neurospora crassa. A report of the U.S. environmental protection agency gene-Tox program. Mutat Res. 1984; 133(2):87-134.

48. Doyle MR, Amasino RM. A single amino acid change in the Enhancer of Zeste ortholog CURLF LEAF results in vernalization-independent, rapid flowering in Arabidopsis. Plant Physiol. 2009;151(3):1688-97.

49. Jenuwein $T$, Laible $G$, Dorn $R$, Reuter G. SET domain proteins modulate chromatin domains in Eu- and heterochromatin. Cell Mol Life Sci. 1998; 54(1):80-93.

50. Aquea F, Vega A, Timmermann T, Poupin MJ, Arce-Johnson P. Genomewide analysis of the SET DOMAIN GROUP family in Grapevine. Plant Cell Rep. 2011;30(6):1087-97.

51. Kapazoglou A, Tondelli A, Papaefthimiou D, Ampatzidou H, Francia E, Stanca MA, Bladenopoulos K, Tsaftaris AS. Epigenetic chromatin modifiers in barley: IV. The study of barley polycomb group (PCG) genes during seed development and in response to external ABA. BMC Plant Biol. 2010;10:73.

52. Lei L, Zhou SL, Ma H, Zhang LS. Expansion and diversification of the SET domain gene family following whole-genome duplicationa in Populus trichocarpa. BMC Evol Biol. 2012;12:51.

53. Ng DWK, Wang T, Chandrasekharan MB, Aramayo R, Kertbundit S, Hall TC. Plant SET domain-containing proteins: structure, function and regulation. Biochim Biphys Acta. 2007;1769(5-6):316-29.

54. Springer NM, Napoli CA, Selinger DA, Pandey R, Cone KC, Chandler VL, Kaeppler HF, Kaeppler SM. Comparative analysis of SET domain proteins in maize and Arabidopsis reveals multiple duplications preceding the divergence of monocots and dicots. Plant Physiol. 2003;132(2):907-25.

55. Zhang LS, Ma H. Complex evolutionary history and diverse domain organization of SET proteins suggest divergent regulatory interactions. New Phytol. 2012;195(1):248-63.

56. Thorstensen T, Grini PE, Aalen PB. SET domain proteins in plant development. Biochim Biophys Acta. 2011;1809(8):407-20.

57. Yun JY, Tamada Y, Kang YE, Amasino RM. ARABIDOPSIS TRITHORAXRELATED3/SET DOMAIN GROUP2 is required for the winter-annual habit of Arabidopsis thaliana. Plant Cell Physiol. 2012;53(5):834-46.

58. Xu L, Zhao Z, Dong A, Soubigous-Taconnat L, Renou JP, Steinmetz A, Shen WH. Di- and tri- but not monomethylation on histone $\mathrm{H} 3$ lysine 36 marks active transcription of genes involved in flowering time regulation and other processes in Arabidopsis thaliana. Mol Cell Biol. 2008;28(4):1348-60.

59. Pien S, Fleury D, Mylne JS, Crevillen P, Inzé D, Avramova Z, Dean C, Grossniklaus U. ARABIDOPSIS TRITHORAX1 dynamically regulates FLOWERING LOCUS C activation via histone 3 lysine 4 trimethylation. Plant Cell. 2008;20(3):580-8.

60. Berr A, Xu L, Gao J, Cognat V, Steinmetz A, Dong A, Shen WH. SET DOMAIN GROUP25 encodes a histone methyltransferase and is involved in FLOWERING LOCUS C activation and repression of flowering. Plant Physiol. 2009;151(3):1476-85.

61. Berr A, Shafig S, Pinon V, Dong AW, Shen WH. The trxG family histone methyltransferase SET DOMAIN GROUP 26 promotes flowering via a distinctive genetic pathway. Plant J. 2015;81(2):316-28.

62. Liu B, Wei G, Shi JL, Jin J, Shen T, Ni T, Shen WH, Yu Y, Dong A. SET DOMAIN GROUP 708, a histone H3 lysine 36-specific methyltransferase, controls flowering time in rice (Oryze sativa). New Phytol. 2016;210(2):57788.

63. Sun CH, Fang J, Zhao TL, Xu B, Zhang FT, Liu LC, Tang JY, Zhang GF, Deng XJ, Chen F, Qian Q, Cao XF, Chu CC. The histone methyltransferase SDG724 mediates H3K36me2/3 deposition at MADS50 and RFT1 and promotes flowering in rice. Plant Cell. 2012;24(8):3235-47.

64. Sui PF, Shi JL, Cao XY, Shen WH, Dong A. H3K36 methylation is involved in promoting rice flowering. Mol Plant. 2013;6(3):975-7.

65. Margueron R, Reinberg D. The Polycomb complex PRC2 and its mark in life. Nature. 2011:469(7330):343-9.

66. Shu J, Chen C, Thapa RK, Bian SM, Nguyen V, Yu KF, Yuan ZC, Liu J, Kohalmi SE, Li CL, Cui YH. Genome-wide occupancy of histone H3K27 methyltransferases CURLY LEAF and SWINGER in Arabidopsis seedlings. Plant Direct. 2019;3(1):e00100.

67. Bouyer D, Roudier F, Heese M, Andersen ED, Gey D, Nowack MK, Goodrich J, Renou JP, Grini PE, Colot V, Schnittger A. Polycomb repressive complex 2 controls the embryo-to-seedling phase transition. PLoS Genet. 2011;7(3): e1002014.

68. He CS, Chen XF, Huang H, Xu L. Reprogramming of H3K27me3 is critical for acquisition of pluripotency from cultured Arabidopsis tissues. PLoS Genet. 2012;8(8):e1002911. 
69. Lafos M, Kroll P, Hohenstatt ML, Thorpe FL, Clarenz O, Schubert D. Dynamic regulation of $\mathrm{H} 3 \mathrm{~K} 27$ trimethylation during Arabidopsis differentiation. PLoS Genet. 2011;7(4):e1002040.

70. Lu FL, Cui X, Zhang SB, Jenuwein T, Cao XF. Arabidopsis REF6 is a histone H3 lysine 27 demethylase. Nat Genet. 2011;43(7):715-9.

71. Schubert D, Primavesi L, Bishopp A, Roberts G, Doonan J, Jenuwein T, Goodrich J. Silencing by plant Polycomb-group genes requires dispersed trimethylation of histone $\mathrm{H3}$ at lysine 27. EMBO J. 2006;25(19):4638-49.

72. Zheng BL, Chen XM. Dynamics of histone H3 lysine 27 trimethylation in plant development. Curr Opin Plant Biol. 2011;14(2):123-9.

73. De Lucia F, Crevillen P, Jones AME, Greb T, Dean C. A PHD-polycomb repressive complex 2 triggers the epigenetic silencing of FLC during vernalization. Proc Natl Acad Sci U S A. 2008;105(44):16831-6.

74. Jiang DH, Wang YQ, Wang YZ, He YH. Repression of FLOWERING LOCUS C and FLOWERING LOCUS T by the Arabidopsis polycomb repressive complex 2 components. PLoS One. 2008;3(10):e3404.

75. Lopez-Vernaza M, Yang SX, Müller R, Thorpe F, de Leau E, Goodrich J. Antagonistic roles of SEPALLATA3, FT and FLC genes as targets of the polycomb group gene CURLY LEAF. PLoS One. 2012;7(2):e307159.

76. Schönrock N, Bouveret R, Leroy O, Borghi L, Köhler C, Gruissem W, Hennig L. Polycomb-group proteins repress the floral activator AGL19 in the FLCindependent vernalization pathway. Genes Dev. 2006;20(12):1667-78.

77. Wood CC, Robertson M, Tanner G, Peacock WJ, Dennis ES, Helliwell CA. The Arabidopsis thaliana vernalization response requires a polycomb-like protein complex that also includes VERNALIZATION INSENSITIVE 3. Proc Natl Acad Sci U S A. 2006;103(39):14631-6.

78. Crevillén P, Yang H, Cui X, Greeff C, Trick M, Qiu Q, Cao XF, Dean C. Epigenetic reprogramming that prevents transgenerational inheritance of the vernalized state. Nature. 2014;515(7528):587-90.

79. Wu HW, Deng SL, Xu HY, Mao HZ, Liu J, Niu QW, Wang H, Chua NH. A noncoding RNA transcribed from the AGAMOUS (AG) second intron binds to CURLY LEAF and represses AG expression in leaves. New Phytol. 2018; 219(4):1480-91.

80. Payá-Milans M, Poza-Viejo L, Martín-Uriz PS, Lara-Astiaso D, Wilkinson MD, Crevillén P. Genome-wide analysis of the H3K27me3 epigenome and transcriptome in Brassica rapa. Gigascience. 2019:8(12):giz147.

81. Liu J, Deng S, Wang H, Ye J, Wu HW, Sun HX, Chua NH. CURLY LEAF regulates genes coordinating seed and lipid biosynthesis. Plant Physiol. 2016;171(1):424-36.

82. Huang SN, Liu WJ, XU JJ, Liu ZY, Li CY, Feng H. Two SAP function in pistil development was proved by two allelic mutations in Chinese cabbage (Brassica rapa L. ssp. pekinensis). BMC Plant Biol. 2020;20:538.

83. Fu W, Ye XL, Ren J, Li QQ, Du JT, Hou AL, Mei FB, Feng H, Liu ZY. Fine mapping of $/ \mathrm{cml}$, a gene conferring chlorophyll-deficient golden leaf in Chinese cabbage (Brassica rapa ssp. pekinensis). Mol Breeding. 2019;39(4):52.

84. Wang N, Zhang Y, Huang SN, Liu ZY, Li CY, Feng H. Defect in Brnym1, a magnesium-dechelatase protein, causes a stay-green phenotype in an EMSmutagenized Chinese cabbage (Brassica campestris L. ssp. pekinensis) line. Hortic Res. 2020;7:8.

85. Yu Y, Zhang FL, Zhao XY, Zhang DS, Zhang ZX. Rapid identification method of late bolting character in Chinese cabbage. China Vegetables. 2004;2004: $16-8$.

86. Li H, Durbin R. Fast and accurate short read alignment with BurrowsWheeler transform. Bioinformatics. 2009;25(14):1754-60.

87. Li H, Handsaker B, Wysoker A, Fennell T, Ruan J, Homer N, Marth G, Abecasis G, Durbin R. The sequence alignment/map format and SAMtools. Bioinformatics. 2009;25(16):2078-9.

88. McKenna A, Hanna M, Banks E, Sivachenko A, Cibulskis K, Kernytaky A, Garimella K, Altshuler D, Gabriel S, Daly M, DePristo MA. The Genome Analysis Toolkit: a MapReduce framework for analyzing next-generation DNA sequencing data. Genome Res. 2010;20(9):1297-303.

89. Wang K, Li MY, Hakonarson H. ANNOVAR: functional annotation of genetic variants from high-throughput sequencing data. Nucleic Acids Res. 2010; 38(16):e164

90. Livak KJ, Schmittgen TD. Analysis of relative gene expression data using real-time quantitative $P C R$ and the 2 (-Delta Delta $C(T)$ ) method. Methods. 2001;25(4):402-8.

91. Ji RQ, Ge WJ, Wang HM, Zhao Y, Feng H. BrSK13, a multiple-allele-inherited male sterility-related gene in Chinese cabbage (Brassica rapa L. ssp. pekinensis), affects pollen development and pollination/fertilization process. Gene. 2019;696:113-21.
92. Pertea M, Kim D, Pertea GM, Leek JT, Salzberg SL. Transcript-level expression analysis of RNA-Seq experiments with HISAT, StringTie, and Ballgown. Nat Protoc. 2016;11(9):1650-67.

93. Ashburner M, Ball CA, Blake JA, Botstein D, Butler H, Cherry JM, Davis AP, Dolinshi K, Dwight SS, Eppig JT, Harris MA, Hill DP, Issel-Tarver L, Kasarskis A, Lewis S, Matese JC, Richardson JE, Ringwald M, Rubin GM, Sherlock G. Gene ontology: tool for the unification of biology. The gene ontology consortium. Nat Genet. 2000;25(1):25-9.

94. Kanehisa M, Araki M, Goto S, Hattori M, Hirakawa M, Itoh M, Katayama T, Kawashima S, Okuda S, Tokinatsu Y, Yamanishi Y. KEGG for linking genomes to life and the environment. Nucleic Acids Res. 2008;36(Database issue): D480-454.

\section{Publisher's Note}

Springer Nature remains neutral with regard to jurisdictional claims in published maps and institutional affiliations.
Ready to submit your research? Choose BMC and benefit from:

- fast, convenient online submission

- thorough peer review by experienced researchers in your field

- rapid publication on acceptance

- support for research data, including large and complex data types

- gold Open Access which fosters wider collaboration and increased citations

- maximum visibility for your research: over $100 \mathrm{M}$ website views per year

At BMC, research is always in progress.

Learn more biomedcentral.com/submissions 